\title{
Appropriate Inhibition of Orexigenic Hypothalamic Arcuate Nucleus Neurons Independently of Leptin Receptor/STAT3 Signaling
}

\author{
Heike Münzberg, ${ }^{1}$ Erin E. Jobst, ${ }^{2}$ Sarah H. Bates, ${ }^{1}$ Justin Jones, ${ }^{1}$ Eneida Villanueva, ${ }^{1}$ Rebecca Leshan, ${ }^{1}$ \\ Marie Björnholm, ${ }^{1}$ Joel Elmquist, ${ }^{3}$ Mark Sleeman, ${ }^{4}$ Michael A. Cowley, ${ }^{2}$ and Martin G. Myers Jr ${ }^{1}$ \\ ${ }^{1}$ Internal Medicine, University of Michigan, Ann Arbor, Michigan 48109, ${ }^{2}$ Oregon National Primate Research Center, Oregon Health and Science University, \\ Beaverton, Oregon 97239, ${ }^{3}$ Department of Medicine/Endocrinology, Harvard Medical School, Boston, Massachusetts 02215 , and ${ }^{4}$ Obesity and Diabetes \\ Research, Regeneron Pharmaceuticals Inc., Tarrytown, New York 10591
}

Leptin directly suppresses the activity of orexigenic neurons in the hypothalamic arcuate nucleus (ARC). We examined c-Fos-like immunoreactivity (CFLIR) as a marker of ARC neuronal activity in $d b / d b$ mice devoid of the signaling form of the leptin receptor (LRb) and $s / s$ mice that express $\mathrm{LRb}^{\mathrm{S1} 138}$ [which is defective for STAT3 (signal transducer and activator of transcription) signaling]. Both $d b / d b$ and $s / s$ animals are hyperphagic and obese. This analysis revealed that CFLIR in agouti related peptide-expressing orexigenic ARC neurons is basally elevated in $d b / d b$ but not $s / s$ mice. Consistent with these observations, electrophysiologic evaluation of a small number of neurons in $s / s$ animals suggested that leptin appropriately suppresses the frequency of IPSCs on ARC proopiomelanocortin (POMC) neurons that are mediated by the release of GABA from orexigenic ARC neurons. CFLIR in POMC neurons of $s / s$ mice was also increased compared with $d b / d b$ animals. Thus, these data suggest that, although $\mathrm{LRb} \rightarrow \mathrm{STAT} 3$ signaling is crucial for the regulation of feeding, it is not required for the acute or chronic regulation of orexigenic ARC neurons, and the activation of STAT3-mediated transcription by leptin is not required for the appropriate development of leptin responsiveness in these neurons.

Key words: leptin; signaling; AgRP; c-Fos; arcuate nucleus; hypothalamus; STAT3

\section{Introduction}

The adipocyte-derived hormone leptin modulates feeding and energy expenditure by regulating the leptin receptor (LRb)expressing neurons in the hypothalamus and elsewhere in the brain (Elmquist et al., 1999; Schwartz et al., 2000; Friedman, 2002; Myers, 2004). Absence of leptin or LRb (in $o b / o b$ and $d b / d b$ mice, respectively) results in dysregulation of LRb-expressing neurons and their targets, leading to hyperphagia, obesity, and neuroendocrine dysfunction. Within the arcuate nucleus of the hypothalamus (ARC), leptin directly and divergently regulates two distinct populations of LRb-expressing neurons, activating anorexigenic proopiomelanocortin (POMC) neurons and promoting their expression of POMC. In contrast, leptin inhibits the neuropeptide gene expression and activity of orexigenic agoutirelated peptide (AgRP)/neuropeptide $\mathrm{Y}(\mathrm{NPY})$-producing neu-

\footnotetext{
Received July 25, 2006; revised Nov. 15, 2006; accepted Nov. 15, 2006.

This work was supported by National Institutes of Health Grants DK56731 and DK57768 (M.G.M.), RR0163 and DK62202 (M.A.C.), and DK53301 and DK56116 (J.E.), American Diabetes Association grants (M.G.M.), and American Heart Association Grant AHA0535298N (H.M.).

Correspondence should be addressed to Dr. Martin G. Myers Jr, Division of Metabolism, Endocrinology, and Diabetes, Departments of Internal Medicine and Physiology, University of Michigan Medical School, 1150 West Medical Center Drive, 4240 MSRB 3, Ann Arbor, MI 48109-0638. E-mail: mgmyers@umich.edu.

J. Elmquist's present address: Center for Hypothalamic Research, Department of Internal Medicine, The University of Texas Southwestern Medical Center, Dallas, TX 75390-9077.

E. E. Jobst's present address: Pacific University, 2043 College Way, Forest Grove, OR 97116.

DOI:10.1523/JNEUROSCI.3168-06.2007

Copyright $\odot 2007$ Society for Neuroscience $\quad$ 0270-6474/07/270069-07\$15.00/0
}

rons (Elias et al., 1999; Schwartz et al., 2000; Cowley et al., 2001; van den Top et al., 2004). Several recent studies have implicated these AgRP-expressing neurons in the promotion of feeding (Gropp et al., 2005; Luquet et al., 2005). Despite a large number of studies investigating leptin action on these two neuronal groups, however, the molecular mechanisms underlying the divergent actions of leptin on these two populations are essentially unknown.

Leptin binding to LRb initiates intracellular signaling by activating the LRb-associated Jak2 (Janus kinase 2) tyrosine kinase, resulting in Jak2 autophosphorylation and the phosphorylation of intracellular tyrosine residues on LRb (Bjorbaek et al., 1997; White et al., 1997; Banks et al., 2000; Kloek et al., 2002). Phosphorylated $\mathrm{Tyr}_{1138}$ of $\mathrm{LRb}$ recruits the latent transcription factor STAT3 (signal transducer and activator of transcription 3), resulting in its phosphorylation and activation to mediate the transcription of POMC and other genes (Vaisse et al., 1996; White et al., 1997; Banks et al., 2000; Bates et al., 2003; Munzberg et al., 2003). Tyr $_{1077}$ may also control the activation of STAT5 during leptin signaling (Hekerman et al., 2005). Other leptin signals, such as phosphatidylinositol 3-kinase (PI3K) (Niswender et al., 2001; Xu et al., 2005b), mammalian target of rapamycin (mTOR) (Cota et al., 2006), and AMP-activated protein kinase (AMPK) (Minokoshi et al., 2004), are activated via currently unknown mechanisms. It is not yet clear how these different LRb signaling pathways are translated into neuronal functions within brain circuits, however. 
Whereas $s / s$ mice that lack only the LRb/STAT3 signal resemble $d b / d b$ mice (which lack all LRb signaling) with regard to body weight and energy homeostasis, they are slightly less obese and exhibit improved glucose homeostasis and reproductive, growth, and immune function compared with $d b / d b$ mice (Bates et al., 2003, 2004, 2005; Dunn et al., 2005). In this study, we examined the activity of the orexigenic AgRP/NPY ARC neurons in $s / s$ and $d b / d b$ mice by studying c-Fos-like immunoreactivity (CFLIR) in ARC AgRP-expressing neurons. We also assessed the ability of leptin to block inhibitory inputs onto ARC POMC neurons, which are mediated by orexigenic ARC neurons, including AgRP/ NPY neurons (Cowley et al., 2001). This analysis demonstrated that $\mathrm{LRb} \rightarrow$ STAT3 signaling is not required for the acute or chronic inhibition of orexigenic ARC neuronal activity.

\section{Materials and Methods}

Materials

Leptin was purchased from Sigma (St. Louis, MO), rabbit anti-cFos was from Oncogene Sciences (Uniondale, NY), goat anti- $\beta$-galactosidase ( $\beta$ Gal) was from Biogenesis (Poole, UK), and donkey serum, biotinylated donkey anti-goat, and donkey anti-rabbit were from Jackson ImmunoResearch (West Grove, PA). Alexa 488-conjugated donkey anti-rabbit and Alexa 564-conjugated streptavidin were purchased from Invitrogen (Carlsbad, CA). ABC Vectastain Elite kit was purchased from Vector Laboratories (Burlingame, CA). All other immunohistochemical supplies were purchased from Sigma.

\section{Animals}

Animals for immunohistochemical, phenotypical, and gene expression analysis were bred in our colony in the Unit for Laboratory Animal Medicine at the University of Michigan. Heterozygote $d b /+$ or $s /+$ mice were bred with heterozygote mice expressing LacZ from the AgRP locus $(a /+)$ or from the Pomc locus $(\mathrm{p} /+)$ (Wortley et al., 2005) to obtain homozygote $d b / d b, s / s$, and $+/+$ mice heterozygous for the AgRP-LacZ or the POMC-LacZ locus. Mice were housed in groups of 2-4 with ad libitum access to food and water, except, when indicated, some mice were fasted overnight $(\sim 16 \mathrm{~h})$ before being killed. For immunohistochemical analysis, ad libitum-fed animals remained with food in the cage until the time of death between 9:00 A.M. and 12:00 P.M.. Fasted animals had food removed before lights out the night before death and were killed between 9:00 A.M. and 12:00 P.M. No effect of the number of animals per cage was observed on ARC CFLIR. All procedures were in accordance with the guidelines and approval of the University Committee on the Care and Use of Animals at the University of Michigan.

For electrophysiological experiments, heterozygous $s /+$ mice were bred with POMC-enhanced green fluorescent protein (EGFP) mice (Cowley et al., 2001) to generate $s /+;$ POMC-EGFP mice, which were then crossed to $s /+$ animals to generated $s / s$;POMC-EGFP animals for study. Mice were housed in the approved animal facility at Oregon National Primate Research Center in groups of two to four with ad libitum access to food and water. All procedures were in accordance with the guidelines and approval of the University Committee on the Care and Use of Animals at Oregon Health and Science University.

\section{Perfusion and immunohistochemistry}

Handling of all animals was limited to $<1 \mathrm{~h}$ before anesthesia and perfusion to minimize stress-related induction of c-Fos levels. Perfusion and immunohistochemistry (IHC) procedures were performed essentially as described previously (Munzberg et al., 2004). Briefly, mice were deeply anesthetized with an overdose of intraperitoneal pentobarbital $(150 \mathrm{mg} /$ $\mathrm{kg}$ ) and transcardially perfused with sterile PBS, followed by $10 \%$ Formalin. Brains were removed, postfixed, and cryoprotected before sectioning into $30 \mu \mathrm{m}$ coronal slices, which were collected into four representative series and stored at $-20^{\circ} \mathrm{C}$ until further use.

For IHC, sections were pretreated in ice-cold methanol, $0.3 \%$ glycine, and $0.3 \%$ SDS and then blocked and incubated in the primary antibodies [rabbit anti-c-Fos $(1: 40,000)$ and/or goat anti- $\beta$-Gal $(1: 3000)]$. Detection of primary antibodies was done by either immunofluorescence
(anti-rabbit-Alexa 488 and anti-goat-biotin followed by streptavidinAlexa 564 conjugate, all 1:200 dilution) or using the avidin-biotin/diaminobenzidine method.

\section{Cell counts and statistics}

For quantification of AgRP neurons and AgRP/c-Fos double-labeled neurons, pictures of the identical areas were taken on channels for Alexa 488 and Alexa 564 from all ARC sections containing AgRP neurons. Using Adobe Photoshop software (Adobe Systems, San Jose, CA), both channels (red and green) were combined in a red-green-blue picture, and single- and double-labeled neurons were counted and recorded digitally to prevent multiple counts. All sections were arranged from rostral to caudal to examine the distribution of double-labeled neurons. Total number of AgRP neurons and AgRP/c-Fos neurons were presented as means \pm SEM, and differences were analyzed by two-way ANOVA followed by a Fisher's PLSD test to determine significant differences between groups. Differences were accepted for $p$ values $<0.05$.

\section{Electrophysiology}

Recordings were made as described previously (Cowley et al., 2001). In brief, brains of 4-week-old $s / s$;POMC-EGFP mice were cut into $185 \mu \mathrm{m}$ coronal sections and maintained in $95 \% \mathrm{O}_{2}$ and $5 \% \mathrm{CO}_{2}$ saturated Krebs' solution (in mm: $126 \mathrm{NaCl}, 2.5 \mathrm{KCl}, 1.2 \mathrm{MgCl}_{2}, 2.4 \mathrm{CaCl}_{2}, 1.2 \mathrm{NaH}_{2} \mathrm{PO}_{4}$, $21.4 \mathrm{NaHCO}_{3}$, and 11.1 glucose) at $35^{\circ} \mathrm{C}$ for at least $1 \mathrm{~h}$ before recordings. POMC-EGFP cells were visualized on an Axioskop 2 FS plus (Zeiss, Oberkochen, Germany), and whole-cell, voltage-clamp recordings (to record whole-cell membrane currents) were made from EGFPexpressing neurons using an Axopatch 200B amplifier (Molecular Devices, Palo Alto, CA) and Clampex version 8.2 (Molecular Devices). GABA-mediated IPSCs were recorded with a CsCl-filled internal electrode (in mM: $140 \mathrm{CsCl}, 10 \mathrm{HEPES}, 5 \mathrm{MgCl}_{2}, 1$ BAPTA, $5 \mathrm{Mg}$-ATP, and $0.3 \mathrm{Na}-$ GTP). Glutamatergic and nonglutamatergic currents were blocked with 25 $\mu \mathrm{M}$ D-APV and $10 \mu \mathrm{M}$ CNQX, respectively, in the extracellular bath. Data was analyzed using Minianalysis (Synaptosoft, Decatur, GA).

\section{Results}

To gain additional insight into the role of the LRb signaling pathways in neuronal function within the CNS, we examined CFLIR by IHC in leptin-responsive hypothalamic and extrahypothalamic sites within the brains of $+/+, d b / d b$, and $s / s$ mice. The expression of Fos is widely used as a surrogate for neuronal activity (Hoffman et al., 1993). In many regions of the brain, there were no clear differences among the various groups; the paraventricular hypothalamic nucleus (PVN), for instance, exhibits high baseline CFLIR that is unaffected by defective LRb signaling (Fig. $1 A)$. We also compared the ventromedial nucleus, dorsomedial nucleus, and the lateral hypothalamus, but no obvious differences could be detected in these hypothalamic sites among the different groups (data not shown). Clearly, it is possible that we overlooked differences in CFLIR in these areas as a result of the inability of CFLIR single labeling to discriminate individual populations of neurons within discrete brain areas. Within the nucleus of the solitary tract (NTS) of the brainstem, we identified groups of neurons that showed increased levels of CFLIR in $d b / d b$ and $s / s$ mice that were absent in $+/+$ mice (Fig. $1 B$ ), suggesting that the disruption of the LRb $\rightarrow$ STAT3 signaling pathway is sufficient to activate these neurons. Gut and vagally derived satiety signals are know to activate neurons in the NTS during and after feeding and are highly active in hyperphagic animals (Morton et al., 2005; Johnstone et al., 2006; Tschop et al., 2006). Thus, although unknown at the present time, these NTS CFLIR-positive neurons in hyperphagic $d b / d b$ and $s / s$ animals may represent such neurons. Indeed, although the size of these obese rodents has prevented the detailed analysis of minute-to-minute food intake (because they become stuck in the feeder tube of most automated feeding systems), our observations suggest that these animals not 
A. PVN

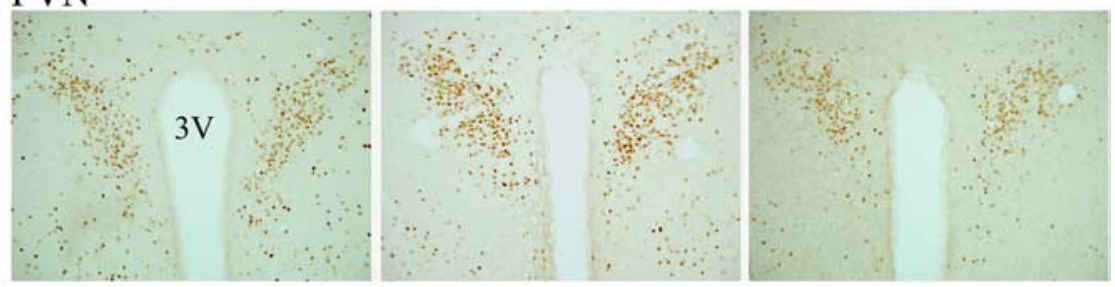

B. NTS

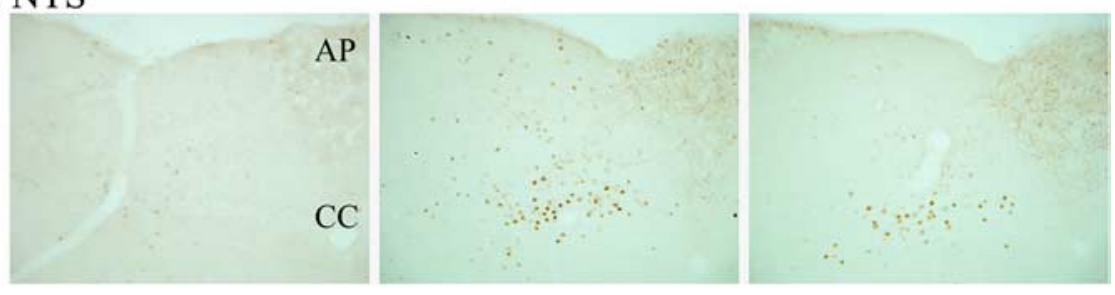

C. ARC
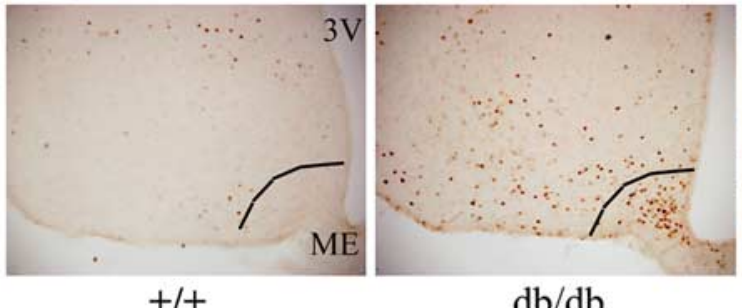

$\mathrm{db} / \mathrm{db}$

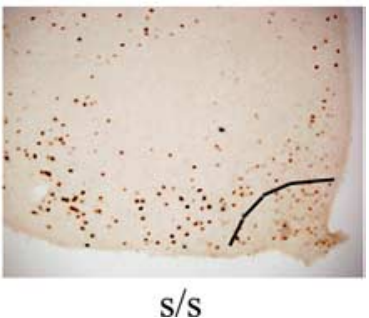

$\mathrm{s} / \mathrm{s}$

Figure 1. Regulation of CNS CFLIR by altered LRb action. Immunohistochemical detection of CFLIR in fed $+/+, d b / d b$, and $s / s$ mice. $\boldsymbol{A}$, Representative sections of the PVN at bregma level $-1.8 \mathrm{~mm}$. $\boldsymbol{B}$, Representative section of the NTS at bregma level $-13.7 \mathrm{~mm}$. C, Representative sections of the ARC at bregma level $-3.0 \mathrm{~mm}$, demonstrating increased CFLIR in the ARC of $d b / d b$ and $s / s$ mice compared with $+/+$ mice. The ventromedial ARC (right of line) of $d b / d b$ mice exhibits a dense population of CFLIR-positive neurons that is essentially absent in s/s mice. CFLIR-DAB-positive neurons are visible as brown nuclei. 3V, Third ventricle; $\mathrm{AP}$, area postrema; $\mathrm{CC}$, central canal; $\mathrm{ME}$, median eminence. Photos taken at $10 \times$ magnification.

only consume more food than $+/+$ animals (Bates et al., 2003, 2004) but also feed during the light cycle, which is not the case for $+/+$ mice (our unpublished observations).

The ARC of both $d b / d b$ and $s / s$ mice displayed dramatically increased CFLIR compared with $+/+$ mice. Here, the pattern of CFLIR clearly differed between $d b / d b$ and $s / s$ animals; however, in the $d b / d b$ mice, there was a distinct ventromedial population of CFLIR-positive cells that was absent in $s / s$ mice (Fig. $1 C$ ). Because the amount and pattern of feeding is similar in $s / s$ and $d b / d b$ animals, differences between these genotypes in the distribution of ARC CFLIR is not likely to represent differences in feeding.

The localization of the CFLIR neurons within the ventromedial ARC of the $d b / d b$ mice suggested that this neuronal population may be the orexigenic AgRP/NPY-expressing neurons, which would be consistent with their activation in fasting, a state of deficient leptin action. To determine whether regulation of these neurons was essentially intact in $s / s$ mice, we examined CFLIR in AgRP-expressing neurons. A variety of factors, including leptin action and nutritional status, can alter AgRP synthesis and secretion. Furthermore, the rapid movement of neuropeptides into the axons, away from the soma, impairs the ability to detect AgRP neurons by anti-peptide IHC. Thus, we used a homologously targeted allele of Agrp containing the coding sequences for $\beta$-Gal to facilitate the detection of AgRP-expressing neurons (Wortley et al., 2005). Mice heterozygous for this allele display no detectable energy balance phenotype but express $\beta$-Gal from the AgRP locus and thus within AgRP neurons. We examined immunofluorescent staining for and colocalization of
CFLIR and $\beta$-Gal (Fig. 2) in fed and fasted $+/+$ mice, as well as in fed $d b / d b$ and $s / s$ mice. As expected (based on the known activation of AgRP neurons by fasting), few AgRP neurons (4\%) were CFLIR positive in ad libitum-fed $+/+$ mice, whereas fasting increased the percentage of CFLIRpositive AgRP neurons to $\sim 60 \%$ (Fig. $2 B$ ). In $d b / d b$ mice, in which AgRP neurons are also expected to exhibit a "fasted" phenotype attributable to deficiency of leptin action, a similar number of AgRP neurons (54\%) displayed CFLIR. In striking contrast, only 9\% of AgRP neurons in $s / s$ mice exhibited CFLIR, demonstrating a dramatic and significant improvement compared with the $d b / d b$ phenotype $(p<0.001)$. Importantly, the percentage of AgRP neurons colabeling for CFLIR was not different between $s / s$ and $+/+$ mice. AgRP/CFLIR neurons, although different in total number among groups, were similarly distributed throughout the ARC in all groups (Fig. $3 C)$. These data are consistent with chronically increased activity of AgRP/ NPY neurons in the absence of LRbmediated repression signals in $d b / d b$ mice and with the improved repression of AgRP and NPY mRNA expression in $s / s$ compared with $d b / d b$ mice (Bates et al., 2003). These results also suggest that the activity of AgRP neurons is primarily suppressed by LRb $\rightarrow$ STAT3-independent LRb signaling pathways.

To examine the leptin-regulated activity of the orexigenic ARC neurons in $s / s$ mice directly, we initially attempted to generate $s / s$ mice containing an NPY-GFP reporter transgene that would permit recording from orexigenic neurons of known phenotype. Our failure to generate homozygous $s / s$ mice containing the reporter gene after extensively interbreeding $s /+$ heterozygous animals containing the transgene suggested the proximity of the site of integration of the NPY-GFP transgene to the leptin receptor locus, however.

We thus chose to examine leptin responsiveness of orexigenic ARC neurons indirectly by generating $s / s$ mice carrying a POMCGFP reporter transgene (Cowley et al., 2001) and examining the effect of leptin on the IPSCs on identified POMC neurons, because these currents are mediated by leptin-inhibited orexigenic neurons, most of which coexpress AgRP and NPY (Cowley et al., 2001). Notably, the frequency of IPSCs onto POMC neurons from $s / s$ animals tended to decrease during leptin treatment (Fig. $3 A, B)$. Overall, leptin treatment tended to decrease IPSC frequency, which gradually returned to near baseline levels within $\sim 10$ min into the washout period. This is consistent with previous reports of leptin action on ARC NPY/AgRP neurons (van den Top et al., 2004) and leptin action on IPSCs onto POMC neurons (Cowley et al., 2001). Of five $s / s$ POMC neurons tested in a single $s / s$ mouse, $40 \%$ showed a response to leptin; this is consistent with previously reported leptin response rates in $+/+$ mice (Cowley et al., 2001). Although given the small number of neurons studied, these results must be considered somewhat preliminary: in context with the previous demonstration that these 
leptin-inhibited IPSCs on ARC POMC neurons are mediated by NPY neurons, these data suggest that the firing of AgRP/ NPY neurons is acutely inhibited by leptin in $s / s$ as in $+/+$ mice. Consistent with the increased activity of POMC neurons in $s / s$ animals, we observed a large number of breakthrough depolarizations in many $s / s$ POMC neurons, limiting our ability to analyze the IPSCs for many recorded neurons (data not shown). Furthermore, IHC examination of CFLIR in POMC neurons from $d b / d b$ and $s / s$ mice heterozygous for a homologously targeted allele of Pomc containing the coding sequences for $\beta-\mathrm{Gal}$ demonstrated a paucity of CFLIR-positive POMC neurons in $d b / d b$ animals but a large number of POMC/CFLIR neurons in the ARC of $s / s$ animals (Fig. 3C). Overall, these data are consistent with improved regulation of POMC neuron activity in $s / s$ compared with $d b / d b$ animals.

\section{Discussion}

Orexigenic ARC neurons, such as those that express AgRP and NPY, are activated by signals of decreased energy stores and fasting, such as ghrelin, and conversely are inhibited by leptin (Elias et al., 1999; Cowley et al., 2003; van den Top et al., 2004; Elmquist et al., 2005). Our finding of chronically elevated CFLIR in ARC AgRP neurons of $d b / d b$ mice devoid of leptin action supports the notion that endogenous leptin at physiologic levels tonically inhibits the depolarization of these neurons in vivo and that lack of leptin signaling in vivo results in chronically increased firing of NPY/AgRP neurons. Increased firing by orexigenic ARC neurons also inhibits anorexigenic ARC POMC neurons (Cowley et al., 2001; Roseberry et al., 2004), presumably contributing to the orexigenic output of the AgRP/NPY neurons.

Other neurons that are distributed throughout the ARC and hypothalamus demonstrate increased CFLIR in $d b / d b$ and $s / s$ animals, and the finding of CFLIRpositive POMC neurons in $s / s$ but not $d b / d b$ mice suggests that these may repre-

sent distinct populations of neurons in each animal model. It is not clear whether this non-AgRP neuron CFLIR represents direct (cell-autonomous) LRb activity or, rather, indirect activity. This is most especially the case in the POMC neurons, in which the increased CFLIR in s/s POMC neurons may represent either decreased orexigenic IPSCs onto the POMC neuron or a cellautonomous effect of the LRb that is expressed in these neurons; it is also possible that these results could reflect a contribution of altered organization of synaptic inputs (Pinto et al., 2004). Because ARC AgRP neurons are known to express LRb (Hahn et al., 1998; Baskin et al., 1999), the regulation of CFLIR in these AgRP neurons is likely to be cell autonomous. Although many inhibitory projections onto POMC neurons derive from ARC AgRP/

A

B

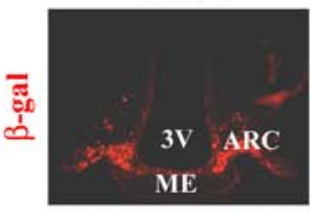

Fasted +/+
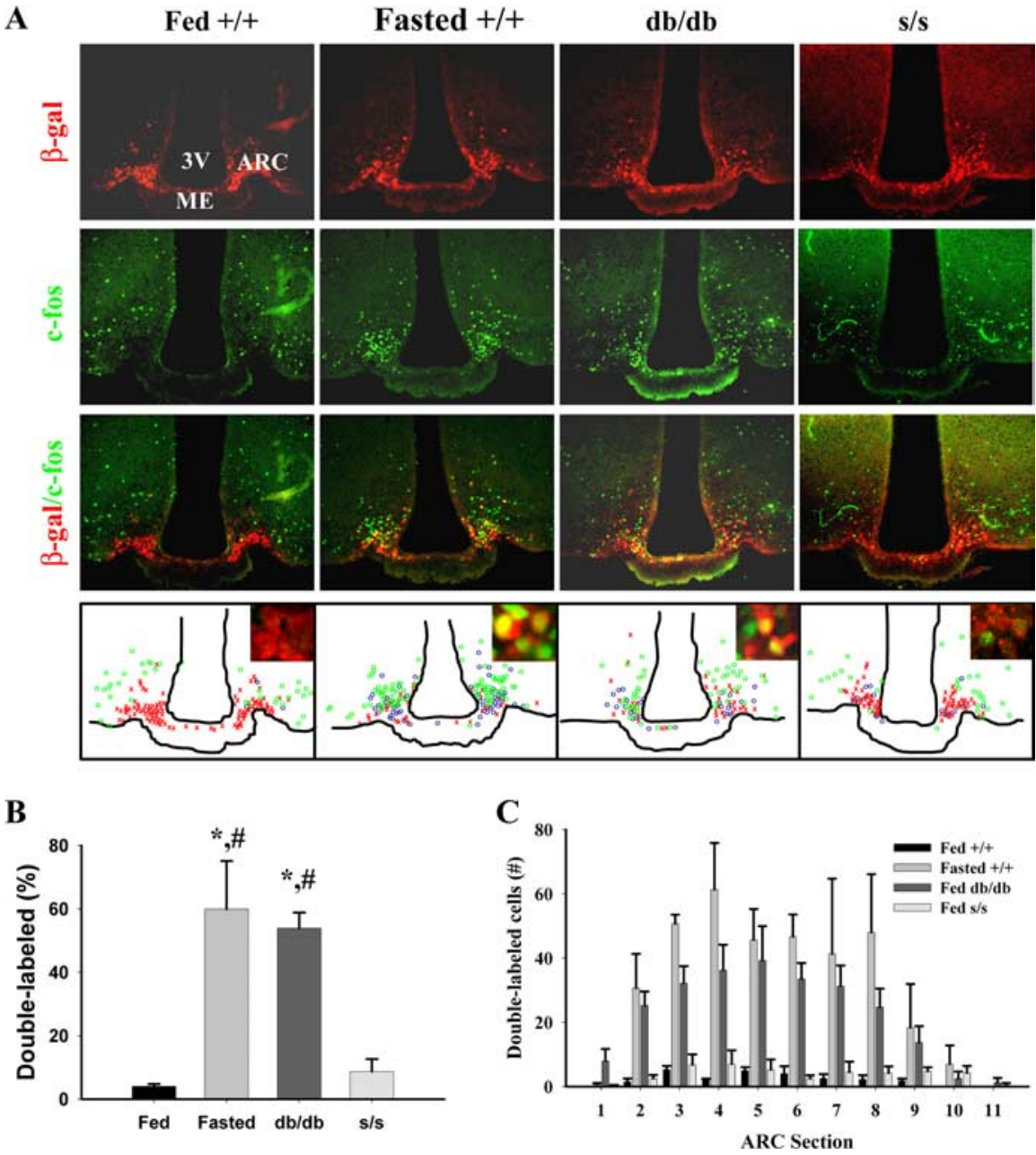

Figure 2. CFLIR in AgRP neurons of fasted $+/+$ and ad libitum-fed $+/+, d b / d b$, and $s /$ s animals. All mouse groups were bred onto a background expressing LacZ under the AgRP promoter, enabling the identification of AgRP neurons by staining for $\beta$-Gal; Representative images showing immunofluorescent detection of c-Fos (green, top), $\beta$-Gal (red, top middle), and merged c-Fos/ tions of AgRP neurons within the ARC. B, Quantification of double-labeled c-Fos/AgRP neurons from animals treated as in $\boldsymbol{A}$. Total 列 $0.001 \mathrm{vs}$ fed $\mathrm{s} / \mathrm{s})$. Differences in total numbers of AgRP neurons within the groups were tested using ANOVA analysis $(p=0.21)$ and Fisher's PLSD and showed no significant differences among the groups, although the number of AgRP-positive neurons trended down in $d b / d b$ mice compared with other groups $(p=0.12 \mathrm{vs}+/+)$. Group sizes were $n=4(\mathrm{fed}+/+$, fed $d b / d b$, and fed $s / s$ ) or $n=3$ (fasted $+/+$ ). 3V, Third ventricle; ME, median eminence.

NPY neurons, we cannot be sure under the conditions of the present experiments whether this is the case. Overall, however, our observations are consistent with the notion that the suppression of these currents is appropriate in $s / s$ animals.

Our data also suggest that the suppression of orexigenic ARC neurons by leptin occurs independently of LRb $\rightarrow$ STAT3 signaling, because CFLIR in ARC AgRP neurons is appropriately suppressed and IPSCs onto the few ARC POMC neurons that we were able to examine are appropriately inhibited by leptin. Furthermore, although we cannot determine whether this represents cell-autonomous or indirect regulation, the finding of increased POMC CFLIR in $s / s$ compared with $d b / d b$ animals suggests that STAT3 signaling is not required for the overall appropriate reg- 
A

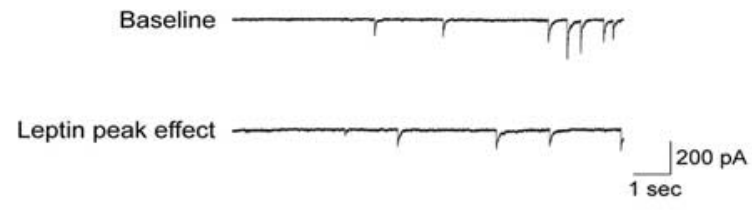

B
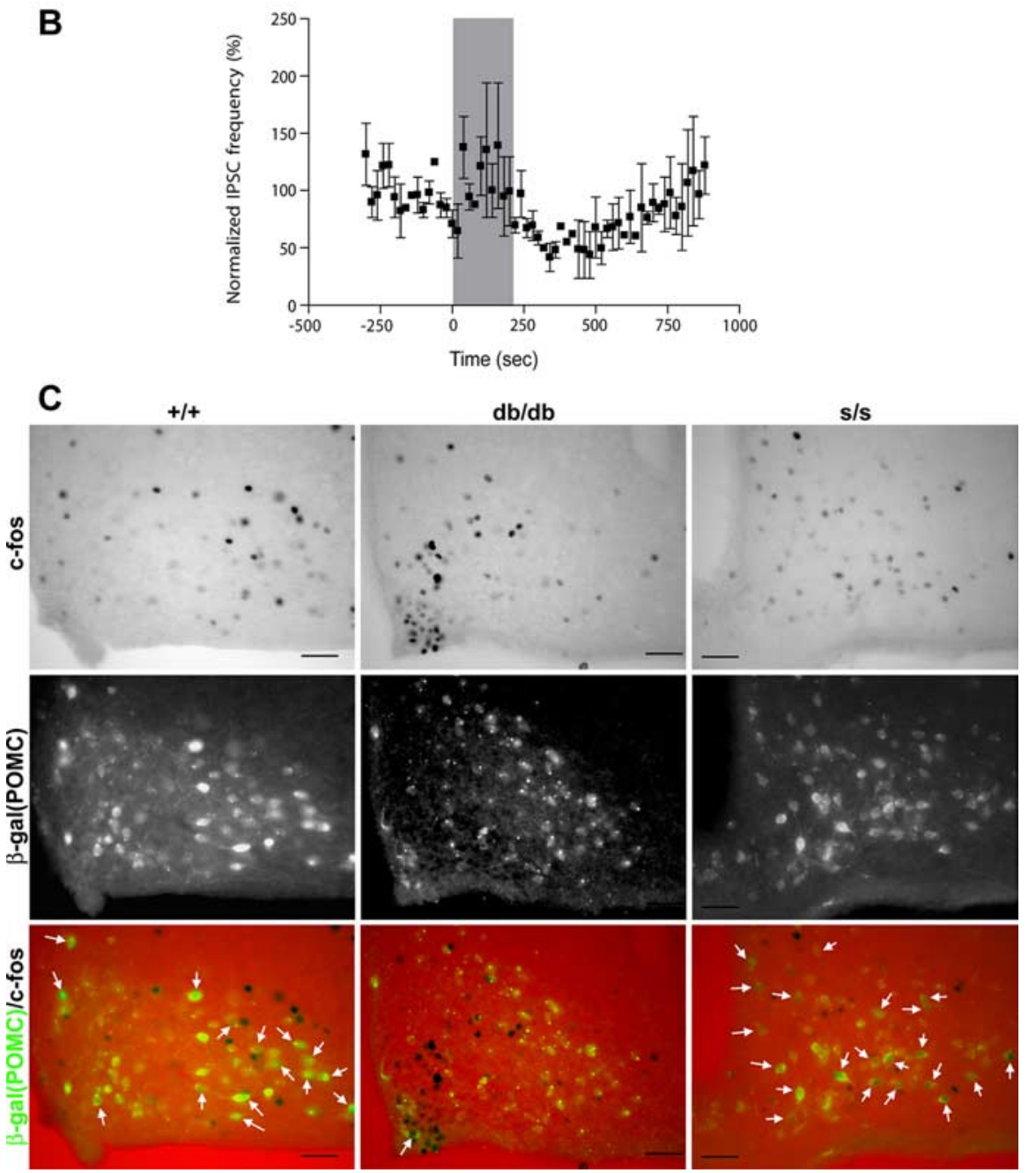

Figure 3. Leptin decreased the frequency of miniature IPSCs onto POMC neurons in s/s mice. $\boldsymbol{A}$, Ten-second sweeps of raw synaptic data from a single POMC neuron showing baseline IPSCs 45 s before (top trace) and $306 \mathrm{~s}$ after (bottom trace) the start of leptin (100 nm) bath application. $\boldsymbol{B}$, Leptin (100 nm) reversibly decreased the inhibitory synaptic input onto POMC neurons from $\mathrm{s} / \mathrm{s}$ animals. The shaded region corresponds to time of drug application $(n=2)$. C, Representative images showing immunohistochemical detection of c-Fos (top, black nuclei) and immunofluorescent detection of $\beta$-Gal (middle, $\beta$-Gal/POMC, green) (bottom is merge) in $\mathrm{db} / \mathrm{db}$ and $\mathrm{s} / \mathrm{s}$ animals with $\beta$-Gal expression in POMC neurons (approximately bregma $-1.9 \mathrm{~mm}$ ). White arrows indicate colocalization of CFLIR with $\beta$-Gal; similar results were seen in multiple independent animals. Scale bars, $5 \mu \mathrm{m}$.

scriptional regulation of genes important for the normal function and electrical leptin responsiveness of these neurons. Other LRbmediated signals that could contribute to the inhibition of AgRP neurons include SHP-2 (phosphatase containing SH2 domains) or Jak2 and/or downstream signals, such as PI3K, mTOR, and AMPK (Niswender et al., 2001; Minokoshi et al., 2004; Myers, 2004; Cota et al., 2006). Indeed, each of these latter signals is potently regulated by leptin in the AgRP neurons of the ARC (Minokoshi et al., 2004; Xu et al., 2005b; Cota et al., 2006), and recent data have defined a role for PI3K signals in the regulation of AgRP mRNA expression (Kitamura et al., 2006).

Overall, our results suggest that, whereas STAT3 signaling is crucial for the regulation of feeding and energy balance (Bates et al., 2003, 2004), the regulation of neuropeptide expression (Bates et al., 2003) and activity in orexigenic ARC neurons is independent of $\mathrm{LRb} \rightarrow$ STAT3 signaling, as may also be the case for activity of anorectic POMC neurons. This does not imply that the activity of orexigenic ARC neurons (and ARC POMC neurons) are not important for leptin action, however. Indeed, ARC AgRP neurons are essential for feeding, because their deletion results in dramatic hypophagia (Bewick et al., 2005; Gropp et al., 2005; Luquet et al., 2005; $\mathrm{Xu}$ et al., 2005a). Furthermore, $s / s$ animals are less obese and tend to eat slightly less than $d b / d b$ mice (Bates et al., 2003, 2004, 2005), and numerous studies have demonstrated important roles for STAT3-independent signaling pathways in the acute anorectic response to leptin (Niswender et al., 2001; Minokoshi et al., 2004; Myers, 2004; Cota et al., 2006), as well as in the regulation of reproduction, growth, immune function, and glucose homeostasis (Bates et al., 2003, 2005; Dunn et al., 2005; Buettner et al., 2006). Thus, STAT3-independent signals may require STAT3 signaling to mediate their full effect but are clearly important physiologically, and this is also likely to be the case for AgRP neuron activity. Indeed, it is likely the case that depolarization of POMC neurons is rather less effective in mediating satiety in $s / s$ animals with low POMC expression than it would be in wild-type animals, as well, be-

ulation of membrane potential in the ARC POMC neurons, as for the AgRP neurons. Although STAT3, a transcription factor, is unlikely to directly and acutely regulate membrane potential during leptin action (because the acute regulation of membrane potential by leptin is rapid and thus unlikely to be mediated by transcription), the finding of appropriate regulation of neuronal activity in the ARC of $s / s$ mice implies not only that the activation of STAT3-mediated transcription by leptin is not required acutely for the regulation of orexigenic ARC neuronal activity but also that $\mathrm{LRb} \rightarrow$ STAT3 signaling is required for neither the approximately normal development of these neurons nor the tran- cause decreased POMC expression results in decreased $\alpha$-melanocyte stimulating hormone, resulting in decreased melanocortin signaling even with normal depolarization of these neurons. The finding of similarly decreased energy expenditure in $s / s$ and $d b / d b$ animals is consistent with a major role for melanocortin action in the regulation of metabolic rate (Butler and Cone, 2002; Bates et al., 2004; Balthasar et al., 2005). Thus, the dramatic obesity resulting from the mutation of the LRb $\rightarrow$ STAT3 signal notwithstanding (Bates et al., 2003), the regulation of AgRP neurons and STAT3independent $\mathrm{LRb}$ signals contribute importantly to the action of leptin in vivo. 
Overall, our present results suggest that, although multiple LRb signals play essential roles in the regulation of energy homeostasis, each leptin signal mediates a subset of neural responses to leptin, and, thus, each LRb signal mediates effects that are important for a distinct subpopulation of LRb-expressing neurons. An understanding of the relationship between individual leptin signals and their cognate neural processes will thus be crucial as we seek to understand the totality of leptin action in the brain.

\section{References}

Balthasar N, Dalgaard LT, Lee CE, Yu J, Funahashi H, Williams T, Ferreira M, Tang V, McGovern RA, Kenny CD, Christiansen LM, Edelstein E, Choi B, Boss O, Aschkenasi C, Zhang CY, Mountjoy K, Kishi T, Elmquist JK, Lowell BB (2005) Divergence of melanocortin pathways in the control of food intake and energy expenditure. Cell 123:493-505.

Banks AS, Davis SM, Bates SH, Myers Jr MG (2000) Activation of downstream signals by the long form of the leptin receptor. J Biol Chem 275:14563-14572.

Baskin DG, Schwartz MW, Seeley RJ, Woods SC, Porte Jr D, Breininger JF, Jonak Z, Schaefer J, Krouse M, Burghardt C, Campfield LA, Burn P, Kochan JP (1999) Leptin receptor long-form splice-variant protein expression in neuron cell bodies of the brain and co-localization with neuropeptide Y mRNA in the arcuate nucleus. J Histochem Cytochem 47:353-362.

Bates SH, Stearns WH, Schubert M, Tso AWK, Wang Y, Banks AS, Dundon TA, Lavery HJ, Haq AK, Maratos-Flier E, Neel BG, Schwartz MW, Myers Jr MG (2003) STAT3 signaling is required for leptin regulation of energy balance but not reproduction. Nature 421:856-859.

Bates SH, Dundon TA, Seifert M, Carlson M, Maratos-Flier E, Myers Jr MG (2004) LRb-STAT3 signaling is required for the neuroendocrine regulation of energy expenditure by leptin. Diabetes 53:3067-3073.

Bates SH, Kulkarni RN, Seifert M, Myers Jr MG (2005) Roles for leptin receptor/STAT3-dependent and -independent signals in the regulation of glucose homeostasis. Cell Metab 1:169-178.

Bewick GA, Gardiner JV, Dhillo WS, Kent AS, White NE, Webster Z, Ghatei MA, Bloom SR (2005) Post-embryonic ablation of AgRP neurons in mice leads to a lean, hypophagic phenotype. FASEB J 19:1680-1682.

Bjorbaek C, Uotani S, da Silva B, Flier JS (1997) Divergent signaling capacities of the long and short isoforms of the leptin receptor. J Biol Chem 272:32686-32695.

Buettner C, Pocai A, Muse ED, Etgen AM, Myers Jr MG, Rossetti L (2006) Critical role of STAT3 in leptin's metabolic actions. Cell Metab 4:49-60.

Butler AA, Cone RD (2002) The melanocortin receptors: lessons from knockout models. Neuropeptides 36:77-84.

Cota D, Proulx K, Smith KA, Kozma SC, Thomas G, Woods SC, Seeley RJ (2006) Hypothalamic mTOR signaling regulates food intake. Science 312:927-930.

Cowley MA, Smart JL, Rubinstein M, Cerdan MG, Diano S, Horvath TL, Cone RD, Low MJ (2001) Leptin activates anorexigenic POMC neurons through a neural network in the arcuate nucleus. Nature 411:480-484.

Cowley MA, Smith RG, Diano S, Tschop M, Pronchuk N, Grove KL, Strasburger CJ, Bidlingmaier M, Esterman M, Heiman ML, Garcia-Segura LM, Nillni EA, Mendez P, Low MJ, Sotonyi P, Friedman JM, Liu H, Pinto S, Colmers WF, Cone RD, Horvath TL (2003) The distribution and mechanism of action of ghrelin in the CNS demonstrates a novel hypothalamic circuit regulating energy homeostasis. Neuron 37:649-661.

Dunn SL, Bjornholm M, Bates SH, Chen Z, Seifert m, Myers Jr MG (2005) Feedback inhibition of leptin receptor/Jak2 signaling via Tyr1138 of the leptin receptor and suppressor of cytokine signaling 3. Mol Endocrinol 19:925-938.

Elias CF, Aschkenasi C, Lee C, Kelly J, Ahima RS, Bjorbaek C, Flier JS, Saper CB, Elmquist JK (1999) Leptin differentially regulates NPY and POMC neurons projecting to the lateral hypothalamic area. Neuron 23:775-786.

Elmquist JK, Elias CF, Saper CB (1999) From lesions to leptin: hypothalamic control of food intake and body weight. Neuron 22:221-232.

Elmquist JK, Coppari R, Balthasar N, Ichinose M, Lowell BB (2005) Identifying hypothalamic pathways controlling food intake, body weight, and glucose homeostasis. J Comp Neurol 493:63-71.

Friedman JM (2002) The function of leptin in nutrition, weight, and physiology. Nutr Rev 60:S1-S14.

Gropp E, Shanabrough M, Borok E, Xu AW, Janoschek R, Buch T, Plum L,
Balthasar N, Hampel B, Waisman A, Barsh GS, Horvath TL, Bruning JC (2005) Agouti-related peptide-expressing neurons are mandatory for feeding. Nat Neurosci 8:1289-1291.

Hahn TM, Breininger JF, Baskin DG, Schwartz MW (1998) Coexpression of Agrp and NPY in fasting-activated hypothalamic neurons. Nat Neurosci 1:271-272.

Hekerman P, Zeidler J, Bamberg-Lemper S, Knobelspies H, Lavens D, Tavernier J, Joost HG, Becker W (2005) Pleiotropy of leptin receptor signalling is defined by distinct roles of the intracellular tyrosines. FEBS J 272:109-119.

Hoffman GE, Smith MS, Verbalis JG (1993) c-Fos and related immediate early gene products as markers of activity in neuroendocrine systems. Front Neuroendocrinol 14:173-213.

Johnstone LE, Fong TM, Leng G (2006) Neuronal activation in the hypothalamus and brainstem during feeding in rats. Cell Metab 4:313-321.

Kitamura T, Feng Y, Kitamura YI, Chua Jr SC, Xu AW, Barsh GS, Rossetti L, Accili D (2006) Forkhead protein FoxO1 mediates Agrp-dependent effects of leptin on food intake. Nat Med 12:534-540.

Kloek C, Haq AK, Dunn SL, Lavery HJ, Banks AS, Myers Jr MG (2002) Regulation of Jak kinases by intracellular leptin receptor sequences. J Biol Chem 277:41547-41555.

Luquet S, Perez FA, Hnasko TS, Palmiter RD (2005) NPY/AgRP neurons are essential for feeding in adult mice but can be ablated in neonates. Science 310:683-685.

Minokoshi Y, Alquier T, Furukawa N, Kim YB, Lee A, Xue B, Mu J, Foufelle F, Ferre P, Birnbaum MJ, Stuck BJ, Kahn BB (2004) AMP-kinase regulates food intake by responding to hormonal and nutrient signals in the hypothalamus. Nature 428:569-574.

Morton GJ, Blevins JE, Williams DL, Niswender KD, Gelling RW, Rhodes CJ, Baskin DG, Schwartz MW (2005) Leptin action in the forebrain regulates the hindbrain response to satiety signals. J Clin Invest 115:703-710.

Munzberg H, Huo L, Nillni EA, Hollenberg AN, Bjorbaek C (2003) Role of signal transducer and activator of transcription 3 in regulation of hypothalamic proopiomelanocortin gene expression by leptin. Endocrinology 144:2121-2131

Munzberg H, Flier JS, Bjorbaek C (2004) Region-specific leptin resistance within the hypothalamus of diet-induced-obese mice. Endocrinology 145:4880-4889.

Myers Jr MG (2004) Leptin receptor signaling and the regulation of mammalian physiology. Recent Prog Horm Res 59:287-304.

Niswender KD, Morton GJ, Stearns WH, Rhodes CJ, Myers Jr MG, Schwartz MW (2001) Intracellular signalling. Key enzyme in leptin-induced anorexia. Nature 413:794-795.

Pinto S, Roseberry AG, Liu H, Diano S, Shanabrough M, Cai X, Friedman JM, Horvath TL (2004) Rapid rewiring of arcuate nucleus feeding circuits by leptin. Science 304:110-115.

Roseberry AG, Liu H, Jackson AC, Cai X, Friedman JM (2004) Neuropeptide Y-mediated inhibition of proopiomelanocortin neurons in the arcuate nucleus shows enhanced desensitization in ob/ob mice. Neuron 41:711-722.

Schwartz MW, Woods SC, Porte Jr D, Seeley RJ, Baskin DG (2000) Central nervous system control of food intake. Nature 404:661-671.

Tschop MH, Castaneda TR, Woods SC (2006) The brain is getting ready for dinner. Cell Metab 4:257-258.

Vaisse C, Halaas JL, Horvath CM, Darnell Jr JE, Stoffel M, Friedman JM (1996) Leptin activation of Stat3 in the hypothalamus of wild-type and $o b / o b$ mice but not $d b / d b$ mice. Nat Genet 14:95-97.

van den Top M, Lee K, Whyment AD, Blanks AM, Spanswick D (2004) Orexigen-sensitive NPY/AgRP pacemaker neurons in the hypothalamic arcuate nucleus. Nat Neurosci 7:493-494.

White DW, Kuropatwinski KK, Devos R, Baumann H, Tartaglia LA (1997) Leptin receptor (OB-R) signaling. J Biol Chem 272:4065-4071.

Wortley KE, Anderson KD, Yasenchak J, Murphy A, Valenzuela D, Diano S, Yancopoulos GD, Wiegand SJ, Sleeman MW (2005) Agouti-related protein-deficient mice display an age-related lean phenotype. Cell Metab 2:421-427.

Xu AW, Kaelin CB, Morton GJ, Ogimoto K, Stanhope K, Graham J, Baskin DG, Havel P, Schwartz MW, Barsh GS (2005a) Effects of hypothalamic neurodegeneration on energy balance. PLoS Biol 3:e415.

Xu AW, Kaelin CB, Takeda K, Akira S, Schwartz MW, Barsh GS (2005b) PI3K integrates the action of insulin and leptin on hypothalamic neurons. J Clin Invest 115:951-958. 